\title{
PENGELOLAAN PROGRAM EKSTRAKURIKULER DI SEKOLAH DASAR NEGERI 005 BINUANG KECAMATAN BANGKINANG KABUPATEN KAMPAR
}

\author{
Heri $^{1)}$ \\ Zulfan Saam ${ }^{2)}$ \\ Isjoni $^{3)}$ \\ Post Graduate Student of Riau University \\ ${ }^{2)}$ Lecturer of Education Management Study Programme PPs University of Riau \\ ${ }^{3}$ Lecturer of Education Management Study Programme PPs University of Riau
}

\begin{abstract}
This research aims to know (1) Planning of extracurricular activities at Public Elementary School 005 Binuang of Bangkinang Sub-district, (2) Organizing extracurricular activities at Public Elementary School Negeri 005 in Binuang, Bangkinang District, (3) Implementation of extracurricular activities at Public Elementary School 005 Binuang, Bangkinang District, (4) Evaluation of extracurricular activities at Public Elementary School 005 Binuang, Bangkinang District, and (5) Inhibiting factors of extracurricular activities at Public Elementary School 005 Binuang, Bangkinang District. This research uses a qualitative approach using descriptive method. Data collection techniques in this study through through observation, interviews, making field notes, observation, and documentation. The data analysis procedure uses a qualitative descriptive analysis strategy model and a qualitative verificative analysis strategy model. Based on the result of the research, it can be concluded that (1) In making the extracurricular activity, the principal holds a meeting together with the teacher and the committee. Then the principal makes the decree shown to the teacher who is given the task as an extracurricular coach who has expertise in the extracurricular field and authorizes (2) The principal together with the extracurricular instructor facilitates the governing structure led by the headmaster directly and assisted by other teachers as the supervisor of the activity, (3) The implementation of this extracurricular activity is done at the school yard involving all the students Selecting their preferred extracurricular activities, (4) In evaluating the principal to assess the outcomes of the extracurricular in the form of student-owned personality and student achievement as a result of their participation in extracurricular activities, and (5) T extracurricular activities such as low student motivation to follow extracurricular activities and low support of parents to children to follow this activity.
\end{abstract}

Key words : Management, Extracurricular Activities

ABSTRAK: Penelitian ini bertujuan untuk mengetahui (1) Perencanaan kegiatan ekstrakurikuler
di Sekolah Dasar Negeri 005 Binuang Kecamatan Bangkinang, (2) Pengorganisasian kegiatan
ekstrakurikuler di Sekolah Dasar Negeri 005 di Binuang Kecamatan Bangkinang, (3)
Pelaksanaan kegiatan ekstrakurikuler di Sekolah Dasar Negeri 005 Binuang Kecamatan
Bangkinang, (4) Evaluasi kegiatan ekstrakurikuler di Sekolah Dasar Negeri 005 Binuang
Kecamatan Bangkinang, dan (5) Faktor penghambat kegiatan ekstrakurikuler di Sekolah Dasar
Negeri 005 Binuang Kecamatan Bangkinang. Penelitian ini menggunakan pendekatan kualitatif
menggunakan metode deskriptif. Teknik pengumpulan data dalam penelitian ini melalui melalui
pengamatan, wawancara, membuat catatan lapangan, observasi, dan dokumentasi. Prosedur 
analisis data menggunakan model strategi analisis deskriptif kualitatif dan model strategi analisis verivikatif kualitatif. Berdasarkan hasil penelitian dapat disimpulkan bahwa (1) Dalam membuat rancangan kegiatan ekstrakurikuler kepala sekolah mengadakan rapat bersama dengan guru dan komite, Kemudian kepala sekolah membuat SK yang ditunjukkan kepada guru yang diberikan tugas sebagai pembina ekstrakurikuler yang memang mempunyai keahlian dalam bidang ektrakurikuler tersebut dan memberi wewenang untuk membuat program kegiatan, (2) Kepala sekolah bersama dengan guru pembina ekstrakurikuler membuat struktur pengurus yang dipimpin oleh kepala sekolah langsung dan dibantu oleh guru-guru lain sebagai pengawas kegiatan, (3) Pelaksanaan kegiatan ektrakurikuler ini dilakukan dihalaman sekolah dengan melibatkan semua murid yang memilih kegiatan ekstrakurikuler yang disukai mereka, (4) Dalam mengevaluasi kepala sekolah menilai hasil dari ekstrakurikuler berupa kepribadian yang dimiliki siswa dan prestasi yang diraih siswa sebagai hasil dari keikut sertaan mereka dalam kegiatan ekstrakurikuler, dan (5) Faktor penghambat kegiatan ekstrakurikuler diantaranya motivasi siswa rendah untuk mengikuti kegiatan ekstrakurikuler dan rendahnya dukungan orang tua terhadap anak untuk mengikuti kegiatan ini.

\section{Kata Kunci : Pengelolaan, Kegiatan Ekstrakurikuler}

\section{PENDAHULUAN}

Kegiatan ekstrakurikuler merupakan wadah yang disediakan oleh satuan pendidikan untuk menyalurkan minat, bakat, hobi, kepribadian, dan kreativitas pesertadidik yang dapat dijadikan sebagai alat untuk mendeteksi talenta peserta didik dan didesain secara profesional sehingga dapat menjadi wahana dalam melahirkan bakat terbesar dalam diri anak, membentuk karakter positif pada siswa, dan tempat aktualisasi diri pada siswa (Anifral, 2008 : 1-2).

Sekolah Dasar Negeri 005 Binuang adalah salah satu Sekolah Dasar Negeri di Kecamatan Binuang Kabupaten Kampar, pada tiap tahun ajaran baru tentunya sekolah memerlukan strategi penerimaan siswa baru yang jitu guna menarik calon siswa, salah satunya dengan mempromosikan apa yang dimiliki sekolah sebagai nilai lebih, seperti memperkenalkan kegiatan ekstrakurikuler unggulan beserta prestasi yang telah diraih sekolah dalam bentuk selebaran, famlet, dan lain-lain. Namun program ini tidak dilaksanakan dikarenakan sekolah tidak aktif dalam melaksanakan program ektrakurikuler, seperti ekstrakurikuler wajib yaitu Pramuka maupun ekstrakurikuler pilihan diantaranya Kesenian, Olahraga, Palang Merah Remaja, Bahasa Inggris, Keagamaan (Seni Baca Tulis Al Qur'an), dan KIR, yang sebenarnya ada dalam program ekstrakulrikuler sekolah tersebut.

Berdasarkan observasi awal peneliti di SD Negeri 005 Binuang, pengelolaan kegiatan ekstrakurikuler yang dilaksanakan di SD Negeri 005 Binuang pada prinsipnya belum terlaksana dengan baik, jadi berkaitan dengan tata kelola atau manajemen kegiatannya masih diperlukan perbaikan di berbagai sisi, misalnya dalam hal peningkatan kualitas dan manajemen pelaksanaan kegiatan ekstrakurikuler. Berkaitan dengan pengelolaan kegiatan ekstrakurikuler di SD Negeri 005 Binuang, hal yang paling mendasar peneliti temukan ialah tidak berjalannya program ektrakurikuler sekolah dengan baik.

Kegiatan ekstrakurikuler adalah bagian yang tak terpisahkan dalam kurikulum. Kegiatan ekstrakurikuler berfungsi untuk mengembangkan minat peserta didik terhadap kegiatan tertentu yang tidak dapat dilaksanakan melalui pembelajaran kelas biasa, serta mengembangkan kemampuan yang terutama berfokus pada kepemimpinan, hubungan social dan kemanusiaan, serta berbagai keterampilan hidup. Kegiatan ekstrakurikuler dilakukan di lingkungan sekolah, didalam masyarakat, maupun alam. Kegiatan ekstrakurikuler wajib dinilai yang hasilnya digunakan sebagai unsur pendukung kegiatan intrakurikuler. (Nana Karyana, M.Pd., Implikasi Kurikulum 2013 Bagi Guru, diakses 
pada hari Jum’at, 13 September 2013 pukul 13.05 WIB).

Prinsip-prinsip kegiatan ekstrakurikuler meliputi: (1) individual, yaitu kegiatan ekstrakurikuler yang sesuai dengan potensi, bakat, dan minat peserta didik masing-masing sekolah, (2) Pilihan, yaitu kegiatan ekstrakurikuler yang sesuai dengan keinginan dan dilaksanakan secara suka rela oleh peserta didik, (3) keterlibatan aktif, yaitu kegiatan ekstrakurikuler yang menuntut keikutsertaan peserta didik secara penuh, (4) menyenangkan, yaitu kegiatan ekstrakurikuler dalam suasana yang disukai dan menggembirakan peserta didik, (5) etos kerja, yaitu kegiatan ekstrakurikuler yang membangun semangat peserta didik untuk bekerja baik dan berhasil, (6) kemamfaatan sosial yaitu kegiatan ekstrakurikuler yang dilaksanakan untuk kepentingan masyarakat.

Kegiatan ekstrakurikuler yang dilakukan di SD Negeri 005 Binuang, seharusnya sekolah dapat melakukan pengembangan-pengembangan kegiatan ekstrakurikuler yang lebih inovatif, lebih memiliki manfaat guna pengembangan karakter siswa yang mengikuti kegiatan ekstrakurikuler tersebut. Selanjutnya bentuk pengembangan tersebut disampaikan atau dikoordinasikan dengan satuan pendidikan guna dilakukan penyusunan panduan tata kelola kegiatan ekstrakurikuler tersebut disekolahan. Setelah melakukan pengkajian dan penyerapan aspirasi dari siswa, satuan pendidikan SD Negeri 005 Binuang bersama-sama dengan guru kelas dan siswa melakukan sharing program kegiatan ekstrakurikuler yang ditawarkan guna mendapatkan gambaran apakah program kegiatan ekstrakurikuler yang telah disusun tersebut dapat berdampak pada pengembangan karakter siswa atau tidak.

Pendidikan karakter merupakan proses untuk menuntun peserta didik menjadi manusia seutuhnya yang berkarakter dalam hati, raga, pikir, serta rasa dan karsa. Pendidikan karakter dapat dimaknai sebagai pendidikan nilai, pendidikan budi pekerti, pendidikan moral, pendidikan watak, yang bertujuan mengembangkan kemampuan peserta didik untuk memberikan keputusan baik buruk, memelihara apa yang baik, dan mewujudkan kebaikan itu dalam kehidupan sehari-hari dengan sepenuh hati (Samani, 2011 : 45).

Idealnya kegiatan ekstrakurikuler menjadi kebanggaan bagi sekolah serta untuk menarik minat masyarakat untuk menyekolah anak mereka di SD Negeri 005 Binuang. Untuk itu kegiatan ektrakurikuler harus dikelola dengan inovasi manajemen yang profesional dan memadai, baik dari segi kualitas maupun kuantitasnya, hasil dari inovasi manajemen ekstrakurikuler secara profesional dapat berdampak pada pengembangan karakter siswa dan diharapkan dapat mendukung pengembangan kompetensi akademik terutama pencapaian KKM(Kriteria Ketuntasan Minimal) dan dapat memberikan kontribusi positif agar siswa menjadi lebih berkualitas, baik secara intelektual, integritas, kreatifitas, dan inovatif didalam perannya berkehidupan bermasyarakat.

Namun kenyataanya, fakta yang diperoleh dari observasi awal

yang dilakukan di SD Negeri 005 Binuang, program ektrakurikuler belum terlaksana dengan baik, ini terjadi akibat dari pengelolaan atau manajemen kegiatan ekstrakurikuler yang belum dikelola dengan baik. Faktor yang menjadi penyebab pengelolaan kegiatan ektrakurikuler terkendala di SD Negeri 005 Binuang diantaranya yaitu kurangnya pendanaan, fasilitas atau sarana prasarana dan tentunya kekurangan jumlah pengampu atau guru pembimbing.

Di beberapa sekolah, banyak kegiatan ekstrakurikuler yang hanya dilaksanakan sebagai kegiatan diluar kegiatan intrakurikuler saja atau dengan kata lain sebagai implementasi pelaksanaan kurikulum, mengingat fungsi ekstrakurikuler adalah sebagai sarana penunjang bagi proses pembelajaran yang dilaksanakan di sekolah yang berguna untuk mengaplikasikan teori dan praktik yang telah diperoleh sebagai hasil nyata proses pembelajaran, namun tujuan pokok dalam rangka pengembangan karakter siswa sedikit dikesampingkan, sehingga kegiatan 
ekstrakurikuler berkesan sebagai pelengkap dari jalannya proses pembelajaran.

Berdasarkan latar belakang masalah di atas, maka penelitian ini difokuskan pada pengelolaan kegiatan ekstrakurikuler di SD Negeri 005 Binuang, dengan subfokus penelitian sebagai berikut :

1. Perencanaan Kegiatan Ekstrakurikuler di Sekolah Dasar Negeri 005 Binuang Kecamatan Bangkinang.

2. Pengorganisasian Kegiatan Ekstrakurikuler di Sekolah Dasar Negeri 005 di Binuang Kecamatan Bangkinang.

3. Pelaksanaan Kegiatan Ekstrakurikuler di Sekolah Dasar Negeri 005 Binuang Kecamatan Bangkinang.

4. Evaluasi Kegiatan Ekstrakurikuler di Sekolah Dasar Negeri 005 Binuang Kecamatan Bangkinang.

5. Faktor Penghambat Kegiatan Ekstrakurikuler di Sekolah Dasar Negeri 005 Binuang Kecamatan Bangkinang.

\section{METODE PENELITIAN}

Berdasarkan tujuan penelitian ini, maka penelitian ini menggunakan pendekatan deskriptif kualitatif. Pendekatan kualitatif dipandang lebih relevan untuk digunakan di dalam mengamati dan menganalisa fenomena-fenomena pengelolaan program ekstrakurikuler di Sekolah Dasar Negeri 005 Binuang Kecamatan Bangkinang Kabupaten Kampar. Pendekatan kualitatif dilaksanakan sebagai upaya memahami situasi tertentu dengan bentuk penelitian studi kasus.

Dalam penelitian ini data dan sumber data yang diambil adalah melalui kepala sekolah, wakil kepala sekolah bidang kesiswaan, pembina ekstrakurikuler, peserta didik, bendahara dana BOS.

Teknik pengumpulan data yang akan dilakukan adalah dengan melalui tahapan sebagai berikut : pengamatan, wawancara, membuat catatan lapangan, dan kajian dokumentasi.

\section{HASIL DAN PEMBAHASAN}

Berdasarkan gambaran umum Sekolah Dasar Negeri 005 Binuang serta informasi yang peneliti peroleh dari informan/sumber data baik melalui wawancara, dokumentasi dan observasi lapangan serta dari rumusan masalah sebagaimana fokus penelitian yang peneliti tetapkan yaitu pengelolaan program ekstrakurikuler di Sekolah Dasar Negeri 005 Binuang Kecamatan Bangkinang Kabupaten Kampar, maka temuan penelitian ini peneliti uraikan menurut subfokus penelitian sebagai berikut:

Subfokus 1 : Perencanaan Kegiatan Ekstrakurikuler di Sekolah Dasar Negeri 005 Binuang

Dari hasil wawancara yang peneliti lakukan baik dengan kepala sekolah dan guru memberikan penjelasan bahwa pada tahap perencanaan sekolah telah membuat rancangan kegiatan ekstrakurikuler sesuai dengan tahaptahap yang telah diatur diantaranya kepala sekolah mengadakan rapat dengan guru dan komite untuk membuta rancangan kegiatan, selajutnya menetapkan SK pembina kegiatan dan melaksankan kegiatan sesuai dengan jadwal yang telah ditentukan. Ada tiga ektrakurikuler yang menjadi kegiatan utama dalam pelaksanaan kegiatan ekstrakurikuer di SD Negeri 005 Binuang diantaranya ekstrakurikuler pramuka, kesenian dan olahraga.

Subfokus 2: Pengorganisasian Kegiatan Ekstrakurikuler di Sekolah Dasar Negeri 005 Binuang

Temuan penelitian mengenai Pengorganisasian kegiatan ekstrakurikuler pramuka di SD negeri 005 Binuang didapat dari wawancara yang dilakukan peneliti dengan kepala sekolah dan majelis guru Dari hasil wawancara tersebut diketahui Setelah peneliti melakukan observasi dokumentasi di SD Negeri 005 Binuang, sekolah belum melakukan pengorganisasian kegiatan pramuka dengan baik, sebab peneliti tidak menemui dokumentasi tentang pengorganisasian pramuka dengan baik sesuai dengan aturan yang benar. 
Subfokus 3: Pelaksanaan kegiatan ekstrakurikuler di SD Negeri 005 Binuang

Berdasarkan hasil wawancara peneliti dengan kepala sekolah, guru dan murid mengenai pelaksanaan kegiatan ekstrakurikuler bahwasanya sekolah telah melaksanakan kegiatan ekstrakurikuler sesuai dengan rancangan dan jadwal yang telah ditentukan oleh sekolah. pelaksanaan kegiatan ekstrakurikuler ini dilaksankan di halaman sekolah dan beberapa ruangan kegiatan yang telah ada disekolah.

Subfokus 4: Evaluasi kegiatan ekstrakurikuler di SD Negeri 005 Binuang Kecamatan Bangkinang.

Dari pengamatan dan wawancara peneliti dengan kepala sekolah dan guru di SD Ngeri 005 Binuang masih banyak hal yang harus ditingkatkan demi pencapaian target atau prestasi sekolah atau siswa dalam kegiatan ekstrakurikuler. Dalam mengevaluasi kegiatan baik Pembina kegiatan ataupun siswa sebagai peserta, kepala sekolah selalu memperhatikan motivasi yang dimiliki siswa atau guru dalam melaksanakan kegiatan ekstrakurikuler, kepala sekolah terus menilai hasil dari ekstrakurikuler berupa kepribadian yang dimilki siswa dan prestasi yang diraih siswa sebagai hasil dari keikut sertaan mereka dalam kegiatan ekstrakurikuler.

Subfokus 5: Faktor penghambat kegiatan ekstrakurikuler di SD Negeri 005 Binuang Kecamatan Bangkinang

Berdasarkan observasi dan wawancara yang peneliti lakukan dengan kepala sekolah dan guru di SD Negeri 005 Binuang terdapat beberapa kendala dalam pelaksanaan kegaiatan ekstrakurikuler, diantaranya motivasi siswa rendah untuk mengikuti kegiatan ekstrakurikuler, selanjutnya faktor orang tua murid merek tidak merasa apa-apa jika anak mereka tidak mengikuti kegiatan ekstrakurikuler, karena merasa kegiatan ekstrakurikuler tidak begitu penting bagi anak-anak mereka dengan materi yang itu-itu saja.

Selain itu masalah pendanaan selalu menjadi tajuk utama dalam pelaksanaan kegiatan pramuka sebab sekolah hanya menganggarkan dana secukupnya untuk kegiatan ekstrakurikuler seperti 4-5\% dari dana BOS untuk 3 jenis kegiatan ekstrakurikuler, sehingga Pembinaan yang dilakukan hanya bisa menyesuaikan program dengan anggaran yang ada.

\section{SIMPULAN DAN SARAN}

1. Aspek perencanaan dengan melakukan beberapa hal, diantaranya: a) kepala sekolah mengadakan rapat dengan guru dan komite sekolah mengenai rancangan kegiatan, b) kepala sekolah meng SK kan guru pembina uang merupakan guru yang berkompeten dan berpengalaman dalam kegiatan ekstrakurikuler yang dirancang, c) guru pembina diberikan wewenang untuk membuat rancangan kegiatan dan sekolah memberikan dana kegiatan yang dibutuhkan. Dilihat dari hasil perencanaan yang dilakukan berdasarka hasil penelitian: a) SD Negeri 005 Binuang belum melakukan prosedur yang baik dan rancangan kegiatan yang baik hanya mengandalkan guru yang ada tanpa penambahan tenaga ahli dari luar sekolah, b) Sekolah tidak memiliki rancangan kegiatan tahunan secara rutin dan jelas, c) Program dibuat hanya untuk melengkapi jam mengajar satu minggu atau hanya dibuat untuk melengkapi kewajiban diadakannya ekstrakurikuler disetiap sekolah dengan bukti tidak adanya data valid mengenai penjadwalan dalam satu semester yang peneliti temui.

2. Aspek pengorganisasian kegiatan ekstrakurikuler sekolah telah melakukan beberapa hal diantaranya: a) dalam pengorganisasisn kegiatan ekstrakurikuler, sekolah belum membuat struktur yang baik dalam pengelolaanya dengan melibatkan segala unsur yang ada disekolah, b) dalam penetapan pembina ekstrakurikuler sekolah menetapkan guru yang berpengalaman dalam bidang ekstrakurikuler tertentu sebagai pembina walau tidak banyak guruguru yang berpengalaman dalam ekstrakurikuler tersebut.

3. Aspek pelaksanaan kegiatan ekstrakurikuler, sekolah telah melakukan 
beberapa hal diantaranya: a) sekolah selalu memberikan motivasi kepada Pembina dan peserta untuk terus semangat dan sungguhsungguh dalam mengikuti kegiatan ekstrakurikuler melalui kepala sekolah. Tidak jarang sekolah memberikan hadiah-hadiah tertentu kepada Pembina dan peserta yang aktif dan berprestasi dalam kegiatan ekstrakurikuler, b) sekolah memberikan pengarahan untuk pelaksanaan kegiatan ekstrakurikuler baik ketika ikut dalam kegiatan maupun pada saat yang lain seperti upaca senin pagi selalu disampaikan untuk selalu aktif dalam kegiatan ekstrakurikuler.

4. Aspek evaluasi, sekolah selalu mengevaluasi kegiatan ekstrakurikuler baik agar berjalan sesuai dengan rancangan dan target yang telah ditetapkan dan memberikan penilaian atas kegiatan yang dilaksanakan sehingga terlihat perkembangan ataupun penurunan kegiatan yang dilaksanakan.

5. Kendala yang dialami sekolah dalam pelaksanaan kegaitan ekstrakurikuler diantaranya siswa yang kurang terhadap kegiatan pramuka, orang tua yang kurang mendukung anaknya untuk mengikuti kegiatan ekstrakurikulker disebabkan tidak faham pentingnya kegiatan ekstrakurikuler dan kemudian sarana dan prasarana yang kurang memadai dan kurang mendukung, solusi untuk menghadapi kendala yang ada sekolah melakukan tindakan dengan mewajibkan semua siswa untuk ikut serta dalam kegiatan ekstrakurikuler, memberikan penyuluhan kepada orang tua tentang pentingnya mengikuti kegiatan ekstrakurikuler dan mencoba melengkapi sarana dan prasarana dengan bertahap.

\section{Saran}

Diharapakan lembaga ini dapat menjaga dan meningkatkan prestasinya, baik prestasi akademik maupun non akademik.

Dapat menjaga dan meningkatkan hubungan dengan pihak-pihak terkait (masyarakat, orang tua dan instansi terkait), sehingga dalam operasional pendidikan dilembaga ini dapat berjalan dengan baik.

Lembaga ini juga diharapkan meningkatkan SDM (personil sekolahnya) dan memberikan pelayanan yang baik, sehingga mereka (para pemakai jasanya) merasa nyaman dan memberikan kesan yang baik terhadap lembaga ini.

\section{A. Bagi kepala sekolah}

Bahwasanya kepala sekolah merupakan orang yang paling bertanggung jawab dalam pelaksanaan proses pendidikan disekolah, sedangkan para wakil kepala sekolah dan para guru merupakan unsur pendukung yang berfungsi membantu kepala sekolah dalam menjalankan tugasnya, oleh karena itu dalam rangka pelaksanaan kegiatan ekstrakurikuler di SD Negeri 005 Binuang agar efektif dan berkualitas, maka diperlukan upaya bersama, yakni antara komponen sekolah dan masyarakat luas yang dimotori oleh kepala sekolah dalam rangka meningkatkan mutu dan kualitas ekstrakurikuler disekolah tersebut.

\section{B. Bagi Para Guru dan Pembinan Pramuka}

Guru merupakan komponen yang paling penting dalam pembelajaran, Oleh karena itu penting sekali adanya kompetensi dan profesionalisme guru dalam mengajar dan membina.

\section{Bagi Komite}

Pelaksanaan kegiatan ekstrakurikuler tidak akan berlangsung sempurna jika tidak ada dukungan yang baik dari setiap komite yang ada di daerah-daerah. Karena kepala sekolah dan stafnya bukan satu-satunya golongan yang memiliki kewajiban untuk menjalankan program ekstrakurikuler. Dengan peran aktif komite sekolah dalam bentuk gagasan maupun peran aktif lainya merupakan solusi yang tepat untuk mewujudkan pelaksanaan kegiatan ekstrakurikuler yang sempurna.
D. Bagi Peneliti Selanjutnya
Bahwa hasil dari analisis tentang pelaksanaan kegiatan ekstrakurikuler di SD 
Negeri 005 Binuang, belum bisa dikatakan final dan sempurna karena masih banyak ditemui kekurangan disana-sini dan kemungkinan lebih banyak kekurangan yang lain yang belum ditemui disebabkan karena kekurangan dan keterbatasan waktu. Sumber rujukan, metode serta ketajaman analisis yang dimiliki peneliti, oleh karena itu diharapkan terdapat peneliti yang mengkaji pelaksanaan kegiatan ekstrakurikuler di SD Negeri 005 Binuang kembali.

\section{DAFTAR PUSTAKA}

Ahmad Syukran, 2016. Evaluasi Program Ekstrakurikuler Kepramukaan pada Jenjang Pendidikan Menengah di Kabupaten Lombok Timur tahun 2016. Jurnal Praktisi Administrasi Pendidikan (JPAP) Volume 1 Number 1, Juli 2016

Anifral Hendri. 2008. Ekskul Olahraga Upaya Membangun karakter Siswa.http:// $\begin{array}{llllllllllllll}2 & 0 & 2 & . & 1 & 5 & 2 & & 3 & 3 & & 8 & 4 & \end{array}$ index.php?option=com_content\&task $=$ view\&id=16421\&Itemid=46. Saturday, 1 November 2008. Pkl: 08.42.WIB.
Asmani, Jamal Ma'mur, 2012. Manajemen Sekolah. Jogjakarta: Diva Press

Depdiknas. 2002. Manajemen Peningkatan Mutu Berbasis Sekolah, Konsep Dasar. Jakarta : Ditjen Pendidikan Dasar dan menengah.

Nana Sudjana. 2004. Dasar-Dasar Proses Belajar Mengajar. Bandung: Sinar Baru Algensindo.

Samani, Muchlas, Hariyanto. 2011. Konsep dan Model Pendidikan Karakter. Bandung : Remaja Rosdakarya.

Siti Ubaidah, 2013. Manajemen Ekstrakurikuler dalam Meningkatkan Mutu Sekolah. Manajemen Pendidikan Suryosubroto. 2009. Proses Belajar Mengajar di Sekolah. Jakarta: PT Rineka. Cipta 